\title{
Human Resource Competencies: Responding to Increased Expectations
}

\author{
Dave Ulrich, Wayne Brockbank, Dani Johnson, and Jon Younger
}

$\mathrm{N}_{\mathrm{ra}}^{\circ}$ o one doubts that the bar has been raised on human resources. The HR profession began with HR professionals focusing on terms and conditions of work so that employees would feel fairly treated. Today, the business world faces enormous change, and HR professionals must do more than manage employee terms and conditions. As the bar has been raised on HR, some lament that HR professionals cannot meet these higher expectations, and HR should be discounted or downsized and its functions automated or outsourced. We believe that instead of denigrating $\mathrm{HR}$, we should upgrade $\mathrm{HR}$ professionals and HR departments to meet the challenges that confront contemporary organizations.

To respond to the raised bar, we propose how HR professionals can respond to increased challenges. We begin with a brief synopsis of the business context that raises new expectations of $\mathrm{HR}$, and then we report the results of our research, on over 10,000 respondents around the world, that defines what HR professionals must know and do to deliver value.

\section{BUSINESS CONTEXT}

In the world of business, familiar themes continually surface. Globalization has made the world a global village, and new markets (particularly in China, India, Brazil, and
Russia) offer new challenges and opportunities. Global issues like trade barriers, exchange rates, tariffs, and distribution become important elements of managerial choice. Technology has increased accessibility, visibility, and connection. The connected world is smaller, rapidly changing, and transparent. Customers have become increasingly segmented, literate, and demanding. Investors have become increasingly attuned to and actively concerned about not only financial results, but also intangibles. Competitors come from both traditional large global players and increasingly smaller investors. Employees represent increasingly diverse demographic backgrounds. In some parts of the world, employees are aging more than in others. Employee expectations are constantly rising as they gain in education and skills.

Most of these trends are outside the control of any one individual or any one company. They occur in both predictable and unpredictable ways. They affect all aspects of business from how to fund a firm to how to position the firm in customers' minds and how to engineer and deliver products. They also affect human resources. HR practices are becoming more integrated, aligned, and innovative. HR departments are operating more like a business within the business, with a clear strategy and channels of distribution. HR professionals are being asked to help 
businesses compete, and to do so, HR professionals must not only observe, but also

HR professionals are being asked to help businesses compete, and to do so, HR professionals must not only oleserve, but also understand and adapt to these business trends.

understand and adapt to these business trends. HR professionals are expected to contribute by the competencies they possess.

\section{HR COMPETENCIES OVERVIEW}

For HR professionals to respond to changing business conditions, they must demonstrate new competencies. HR professionals who would have been successful in previous decades would not be effective today. We have worked for the last 20 years to identify the competencies that enable HR professionals to respond to business conditions. HR competencies are the values, knowledge, and abilities of HR professionals. HR professionals with the right competencies will perform better. They will be more likely to engage employees, to serve customers, and to create intangible shareholder wealth. HR competencies define what is expected from those who work in HR and form the basis for assessment and improvement in the quality of $\mathrm{HR}$ professionals.

Since 1988, we have been working to track the ever-evolving competencies of HR professionals. When we began our work in the mid1980s, the primary effort to study broadbased HR competencies was by Patricia McLagan, sponsored by the American Society of Training and Development (ASTD). Her work initially examined competencies of HR development professionals, and then she generalized that work to all HR professionals. ${ }^{1}$ At the same time, many companies worked to create their own internal HR competency models. This work would generally start by identifying high- and low-performing HR professionals and then interviewing these two groups around critical incidents to determine which values, knowledge, or abilities distinguished the two groups in order to develop competencies that would lead to high performance. $^{2}$

Out of these independent efforts grew many frameworks for HR competencies, but there were relatively few efforts to define $H R$ competencies for HR professionals across firms, industries, or geographies. We began our research on competencies with the desire to resolve three issues:

1. Define the competencies that add greatest value to key stakeholders.

2. Figure out how HR professionals develop these competencies in the fastest and most effective ways.

3. Determine how HR competencies and HR practices align to business performance.

To address these issues for the HR profession, we chose to do a large-scale survey (Human Resources Competency Study, or HRCS) of HR professionals and their HR and non-HR associates. This work has resulted in five waves of data collection (1988, 1992, 1997, 2002, and now 2007). ${ }^{3}$ At each "wave" we used the same basic methodology for data collection based on a 360-degree methodology. We sent surveys to HR professionals (participants), who then gave them to their colleagues (associates). These surveys asked about the competencies and performance of the HR professional and the performance of the business where the HR professional worked. 


\begin{tabular}{lccrrrr}
\hline & U.S. and & Latin & & \multicolumn{3}{c}{ Australia/Asia } \\
\# of Respondents & 2,773 & America & Europe & China & Pacific & India \\
\% of Respondents & 28 & 21 & 1,553 & 2,110 & 1,235 & 263 \\
\hline
\end{tabular}

Exhibit 1. Demographics by Region

\section{Demographic Results}

The 2007 round of our research has about 1,700 participants and 8,300 associate raters in six regions around the world. ${ }^{4}$ The number of respondents by region can be seen in

Exhibit 1.

These respondents represent three groups:

1. Participating HR professionals completed the survey, evaluating themselves.

2. HR professionals who are peers or associates evaluated the participating HR professionals.

3. Non-HR associates who are generally line executives and internal customers evaluated the participating HR professionals

These groups provided the opportunity to look at different perspectives regarding $\mathrm{HR}$ as a profession, the HR department, and the competencies needed by HR professionals to be effective in their organizations.

Exhibit 2 shows the demographics in these data over 20 years. Since these data represent a large cross section of the HR profession, we can make some general observations about the evolving profession.

Gender. There has been a sizeable shift in the number of women in HR. In the last 18 years, the percentage of women in the HR profession has increased from about 20-25 percent to over 50 percent. This percentage reflects not only the number of women who are associates (those who rated the participant), but also those who are HR participants themselves. This may be due to more women entering the workforce and HR being a profession of choice for them.

$\square$ Education. This sample consistently focuses on HR professionals with higher education (78 percent are college educated in 2007 study). Although this number has dropped somewhat compared with previous rounds of the study (87 percent in 2002; 90 percent in 1997), the study continues to draw on HR professionals with higher education ${ }^{5}$ and shows that many HR professionals have obtained advanced education.

- Level of Participant. We classified HR professionals into four levels (loosely consistent with four stages of careers). In the 2007 data, 21 percent of participating HR professionals described themselves as senior HR executives. This may be because the 2007 data set has more smaller firms with fewer HR professionals, but those in place are doing more director-level work.

$\square$ Size of Firm. We started the research focused on larger firms (rounds one and two had 39 percent and 40 percent of respondents in firms with over 10,000 employees), but in the 2007 data, we 


\begin{tabular}{|c|c|c|c|c|c|}
\hline & 1987 & 1992 & 1997 & 2002 & 2007 \\
\hline Total Number of Respondents & 10,291 & 4,556 & 3,229 & 7,082 & 10,063 \\
\hline Number of Business Units & 1,200 & 441 & 678 & 692 & 413 \\
\hline \multicolumn{6}{|l|}{ Respondent } \\
\hline Associate raters & 8,884 & 3,805 & 2,565 & 5,890 & 8,414 \\
\hline HR participant & 1,407 & 751 & 664 & 1,192 & 1,671 \\
\hline \multicolumn{6}{|l|}{ Gender (\%) } \\
\hline Male & 77 & 78 & 70 & 57 & 46 \\
\hline Female & 23 & 22 & 30 & 43 & 54 \\
\hline \multicolumn{6}{|c|}{ Relationship of Associate to Participant (\%) } \\
\hline Supervisor & 12 & 12 & 10 & 16 & 19 \\
\hline Peer & 42 & 41 & 46 & 28 & 30 \\
\hline Subordinate (direct report) & 28 & 26 & 11 & 25 & 27 \\
\hline Client & 18 & 21 & 33 & 28 & 24 \\
\hline Other & & & & 3 & \\
\hline \multicolumn{6}{|l|}{ Education of HR Participant $(\%)$} \\
\hline High school degree & 3 & 7 & 4 & 4 & 9 \\
\hline Associate college degree & 5 & 7 & 6 & 9 & 12 \\
\hline Bachelor's degree & 48 & 43 & 42 & 42 & 37 \\
\hline Graduate degree & 44 & 43 & 48 & 45 & 41 \\
\hline \multicolumn{6}{|l|}{ Level of the HR Participant $(\%)$} \\
\hline Individual contributor & 20 & 24 & 29 & 24 & 28 \\
\hline Manager of individual contributors & 36 & 41 & 34 & 34 & 30 \\
\hline Director of managers & 36 & 29 & 30 & 31 & 20 \\
\hline Top manager & 8 & 6 & 7 & 11 & 21 \\
\hline \multicolumn{6}{|l|}{ Size of HR Participant's Company $(\%)$} \\
\hline $1-499$ & 15 & 17 & 22 & 25 & 31 \\
\hline $500-999$ & 10 & 9 & 13 & 15 & 14 \\
\hline $1,000-4,999$ & 25 & 22 & 34 & 33 & 28 \\
\hline $5,000-9,999$ & 11 & 12 & 11 & 9 & 6 \\
\hline Over 10,000 & 39 & 40 & 20 & 18 & 20 \\
\hline \multicolumn{6}{|c|}{ Years in HR Profession for Participant (\%) } \\
\hline 5 years or less & 10 & 14 & 13 & 25 & 24 \\
\hline $6-9$ years & 14 & 19 & 15 & 18 & 20 \\
\hline $10-14$ years & 26 & 24 & 21 & 22 & 23 \\
\hline 15 or more years & 50 & 43 & 51 & 35 & 32 \\
\hline
\end{tabular}

Exhibit 2. Characteristics of the Human Resource Competency Data Set, 1987-2007 
$\begin{array}{lllll}1987 & 1992 & 1997 & 2002 & 2007\end{array}$

Industry of HR Participant (\%)

Agriculture

Petroleum and mining

Chemicals, allied products, pharmaceuticals

General manufacturing

Automotive

Communications and high tech

Retail and wholesale

Financial services

Services

Utilities

Public administration

Primary Role of HR Participant (\%)

Benefits/medical/safety

Compensation

HR planning/strategy/affirmative action

Labor relations

Org. dev. research, effectiveness

Recruiting

Training/communication

Generalist

$\begin{array}{rrrrr}0 & 0 & 0 & 10 & 6 \\ 6 & 5 & 3 & 7 & 17 \\ 11 & 9 & 7 & 15 & 12 \\ & & & & \\ 28 & 14 & 20 & 5 & 20 \\ 4 & 3 & 1 & 6 & 0 \\ 14 & 14 & 11 & 16 & 7 \\ 14 & 14 & 11 & 8 & 5 \\ 11 & 7 & 27 & 11 & 7 \\ 8 & 15 & 14 & 16 & 20 \\ 4 & 19 & 6 & 3 & 4 \\ 0 & 0 & 0 & 3 & 3 \\ & & & & \\ 6 & 5 & 5 & 4 & 3 \\ 5 & 4 & 4 & 6 & 6 \\ 6 & 8 & 5 & 8 & 14 \\ 6 & 8 & 5 & 6 & 5 \\ 2 & 5 & 3 & 13 & 7 \\ 3 & 6 & 4 & 4 & 6 \\ 7 & 14 & 6 & 12 & 9 \\ 61 & 45 & 60 & 48 & 49\end{array}$

Exhibit 2. Continued.

wanted to also study HR competencies in smaller firms (20 percent of respondents in firms with over 10,000 employees and 31 percent of respondents in firms with fewer than 500 employees).

- Primary Role of HR Participant. In the 2007 study, more HR professionals (14 percent) have titles related to HR strategy or planning. In the last 20 years, more resources have gone into this role as HR has worked to be more aligned with business results. The number of HR professionals doing work in benefits has declined as e-HR and service centers have streamlined benefits operations.

\section{THE NEW HR COMPETENCY MODEL FOR ROUND FIVE HRCS}

To determine the new HR competencies, the 130 questions about behaviors or knowledge that an HR professional might demonstrate were statistically analyzed. This analysis grouped the questions by likeness to yield six distinct competency domains. These domains are defined with the idea that HR competencies include not just knowledge, ability, and values, but also the ability to use this knowledge. We see HR professionals as needing to know, but more importantly, needing to do what they know. Exhibit 3 shows 


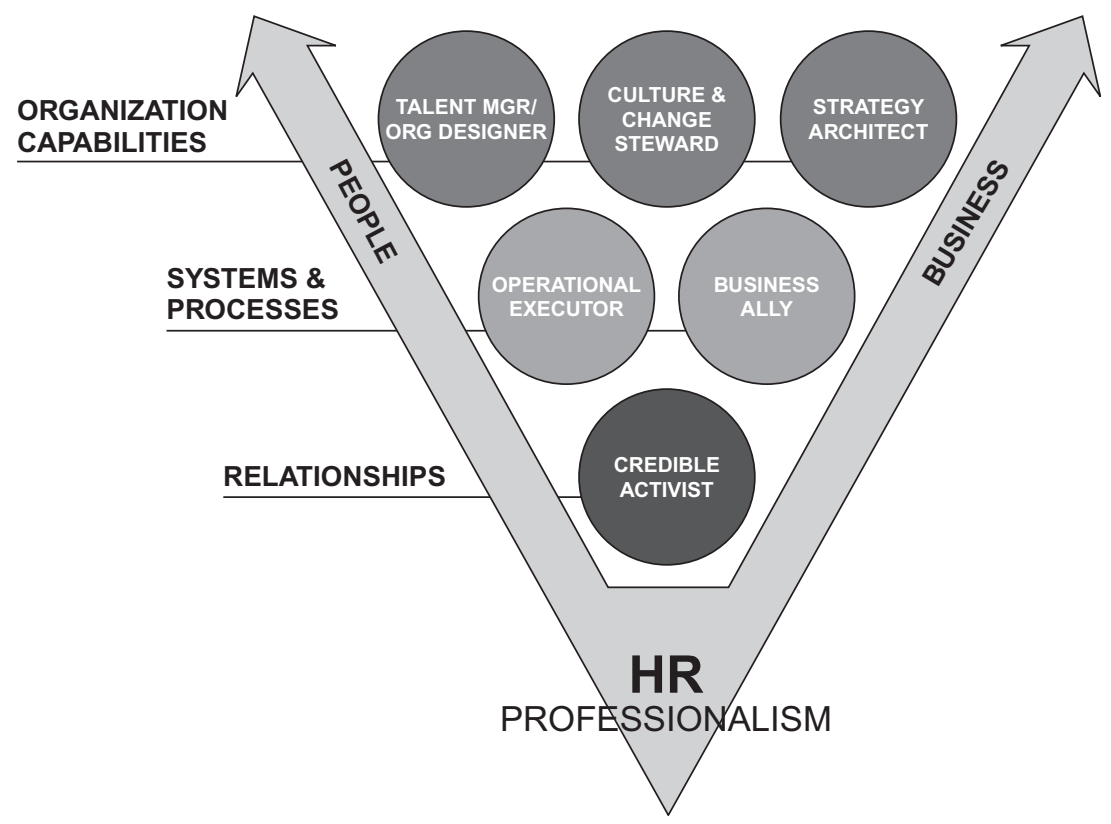

Exhibit 3. HR Competency Model

the Round 5 HR Competency Model, which is further explained below.

This exhibit suggests that HR professionals must master competencies dealing both with people and business issues (large arrows). In changing business conditions, HR professionals should serve the organization's people, communicating care, concern, and compassion for employees. Some have called this the human in human resources. But business conditions also require that HR professionals be attuned to customer and investor expectations by making sure that strategies are designed and delivered. Following one of these two paths independent of the other leads to failure. HR professionals who emphasize the people side at the exclusion of the business side may be well-liked and popular, but they will not succeed, because their work does not further business goals. HR professionals who focus on the business side without sensitivity to the human element will also not succeed because although the business may prosper in the short term, people will not sustain the success in the longer term. Within these two dimensions, we arrayed six domains of HR competence, dealing with relationships, processes, and capabilities. Each is further defined below.

1. Credible Activist. The HR professional is both credible (respected, admired, listened to) and active (offers a point of view, takes a position, challenges assumptions). Some have called this "HR with an attitude." HR professionals who are credible but not activists are admired but do not have much impact. Those who are activists but not credible may have ideas but will not be listened to.

2. Culture and Change Steward. The HR professional appreciates, articulates, and helps shape a company's culture. Culture is a pattern of activities more than a single event. Ideally, this culture starts with clarity around external customer expectations 
(firm identity or brand) and then translates these expectations into internal employee and organization behaviors. As stewards of culture, HR professionals respect the past culture and also can help to shape a new culture. They coach managers in how their actions reflect and drive culture; they weave the cultural standards into HR practices and processes; and they make culture real to employees. Additionally, successful HR professionals facilitate change in two ways. First, they help make culture happen. Second, they develop disciplines to make changes happen throughout the organization. This may include implementation of strategy, projects, or initiatives. They help turn what is known into what is done.

\section{Talent Manager/Organizational}

Designer. The HR professional masters theory, research, and practice in both talent management and organization design. Talent management focuses on competency requirements and how individuals enter and move up, across, or out of the organization. Organization design focuses on how a company embeds capability (for example, collaboration) into the structure, processes, and policies that shape how an organization works. HR professionals ensure that the company's means of talent management and organizational capabilities are aligned with customer requirements and strategy, integrated with each other, and are working effectively and efficiently. HR is not just about talent or organization, but also about the two of them together. Good talent without a supporting organization will not be sustained, and a good organization will not deliver results without talented individuals with the right competencies in critical roles.
4. Strategy Architect. The HR professional has a vision for how the organization can win in the future and plays an active part in the establishment of the overall strategy to deliver on this vision. This means recognizing business trends and their impact on the business, forecasting potential obstacles to success, and facilitating the process of gaining strategic clarity. The HR professional also contributes to the building of the overall strategy by linking the internal organization to external customer expectations. This linkage helps make customer-driven business strategies real to the employees of the company.

As stemards of culture, AR professionals respect the past culture and also can help to shape a nem culture.

5. Operational Executor. The HR professional executes the operational aspects of managing people and organizations. Policies need to be drafted, adapted, and implemented. Employees also have many administrative needs (e.g., to be paid, relocated, hired, and trained). HR professionals ensure that these basic needs are efficiently dealt with through technology, shared services, and/or outsourcing. This operational work of HR ensures credibility if executed flawlessly and grounded in the consistent application of policies.

6. Business Ally. Businesses succeed by setting goals and objectives that respond to external opportunities and threats. HR professionals contribute to the success of a business by knowing the social context or setting in which their business operates. They also know how the business makes money, which we call the value chain of 
the business (who customers are, why they buy the company's products or services). Finally, they have a good understanding of the parts of the business (finance, marketing, research and development, engineering), what they must accomplish, and how they work together, so that they can help the business organize to make money.

\section{KEY FINDINGS}

The findings of Round 5 of the HRCS are divided into three areas: (1) general findings, (2) findings that matter to individual HR professionals, and (3) findings that focus on the HR department. ${ }^{6}$

HR professionals contribute to the success of a business by knowing the social context or setting in which their business operates.

\section{General Findings}

1. Differences in Perception. When we compared results of HR associates versus non-HR associates, two specific differences became apparent:

a. Customer Views for HR. Non-HR associate raters believe that external customers can and should be brought into the HR work. HR respondents did not perceive this. This indicates that HR practitioners may still be defining "customers" as employees and line managers and not as the external customers of the firm. HR professionals need to pay more attention to the real external customers and find ways to bring them into the organization. b. Designing Rewards Systems. Non-HR associate raters seem to see reward systems (compensation, benefits, performance appraisal, etc.) as connected to the HR practices of talent management and organization development. HR associates and participants put reward activities together with operational/tactical items. This is a fascinating difference in opinion. It may be that HR departments are shifting their more strategic work to talent and organization, and compensation is beginning to be more routine and transactional. It may be that compensation and talent management/organization design professionals are becoming separated (compensation people don't attend talent management/organization design conferences, and vice versa). This could be a weakness in building an integrated view of HR practices. Clearly, compensation systems affect or at least reinforce actions of employees, but they may not be as integrated as they could or should be with other HR work.

2. Emerging Markets. The amount of emphasis put on each of the competencies for HR professionals varies by emerging vs. traditional markets. In emerging markets (India, China), HR professionals need to pay more attention to the "Operational Executor" and "Business Ally" skills, whereas in the mature markets these items are seen as table stakes or tickets of admission to the partner role.

\section{Talent Manager and Organization} Designer. In our initial factor analysis, talent and organization items were factored within the same domain, indicating that while they are different, they need to be connected. It is not enough to get good 
people (ergo, a danger of moving to human capital) without an organization that sustains it. This is a significant shift away from the current trend, in wich many HR professionals focus extensively on talent management. Talent management without attention to organization capability is insufficient. This idea is reinforced by the impact that the HR department has on business performance. HR departments account for around 25 percent of business performance, whereas HR competencies of individual HR professionals account for about 20 percent.

4. Culture Steward. In previous rounds of the HRCS, culture was subsumed under "strategic contribution." In Round 5, it formed a unique domain. Evidently, in the last few years HR's ability to define, create, manage, and change culture has become a unique source of competence that HR professionals must demonstrate. Somewhat ironically, this domain is the second-highest-rated in predicting performance of both HR professional and HR department effectiveness /above Strategy Architect and Talent Manager/ Organization Designer). So, HR professionals are being asked to manage culture and they seem to be doing it better than some of the more traditional roles. This may indicate a shift in how HR is viewed.

\section{Findings for the HR Professional}

Business Impact. Based on other research, management has about a 50 percent influence on a firm's performance; the other 50 percent is outside the control of management (economic conditions, competitors' actions, etc.). ${ }^{7} \mathrm{HR}$ is a part of the managerial 50 percent (in addition to choices about strategy, marketing, manufacturing, etc.). The overall impact of what HR professionals know and do has increased in terms of its impact on business performance to roughly 20 percent. So, the competencies of HR professionals account for roughly 20 percent of the 50 percent of managerial impact on business results.

$\square$ More Active Role. Increasingly, business demands place a higher set of expectations on HR professionals. Non-HR professionals want more from HR professionals than ever before.

$\square$ Credible Activist. This domain showed the highest importance in predicting the effectiveness of an HR professional. HR professionals must earn their credibility by building relationships of trust, but they then must take an active stance to make a difference in results. Credibility is not enough without action, particularly action within the other five domains.

AR professionals are being asked to manage culture and they seem to be doing it better than some of the more traditional roles.

$\square$ Culture and Change Steward, Talent Manager/Organization Designer, and Strategy Architect. These three competency domains of HR competence form a collection of things HR professionals must know and do to make a difference. As noted, culture means turning events into patterns. Talent managers ensure a flow of future talent. Organization designers make sure that the organization has the capabilities to compete. Strategy architects help the business develop and implement plans that improve competitiveness and customer relationships. 


\section{$\square$ Business Ally and Operational}

Executor. We find that these competency domains are table stakes. They are necessary but not sufficient. As mentioned above, in emerging markets (China, India), these are more important for the success of the HR professional than in more mature markets, where the managers may assume that HR professionals can and do do these things.

AR professionals must earn their credibility by benilding relationships of trust, lent they then must take an active stance to make a difference in results.

\section{Findings for the HR Department}

HR Department Focus. HR departments have 25 percent more impact on the performance of the business than the competencies of the HR professionals. In previous rounds of the study, we encouraged building the competencies of individual HR professionals; now we also need to make sure that the HR department works well as a functional group.

Stakeholders. HR departments need to focus on a mix of all stakeholders to have a full impact on the business. We assume (but did not test the assumption) that in previous years, HR primarily focused on employees and line managers, but we found that an equal focus on customers, investors, and communities affects business results. It is not enough to have talented HR people; we need capable HR departments. The old adage "I like my HR person; I hate my HR department" may be out of date. We also found that HR departments should build practices and activities with an eye to employees and investors, but they should involve line managers and customers to make things happen.

- HR Organization. When the HR organization is aligned with the business strategy and with the business organization, higher business results follow.

\section{CONCLUSION}

The business context required to succeed has raised the bar on HR professionals. HR professionals who would have succeeded 30, 20, or even 10 years ago would not be as likely to succeed today. HR professionals are expected to play new roles, and to be able to play those roles, they need new competencies. As a result of the Human Resource Competency Study, we have a greater understanding of the competencies needed by HR professionals and agendas needed by HR departments to affect business performance.

\section{NOTES}

1. McLagan, P., \& Bedrick, D. (1983). Models for excellence: The results of the ASTD training and development study.

Training and Development, 37(6), 10-20.

McLagan, P., \& Suhadolnik, D. (1989). Models for HRD practice: The research report. Alexandria, VA: American Society for Training and Development. McLagan, P. (1996, January). Competency models. Training and Development, 50(1), 60-64.

2. An exception to the within-company work was the work done by Patricia McLagan for the American Society for Training and Development in 1983. This important study documented the variety of possible roles for human resource professionals and examined the detailed competencies for those involved in training and development. McLagan, P., \& Bedrick, D. (1983). Models for excellence: The results of the ASTD training and development study. Training and Development, 37(6), 10-20. 
McLagan, P., \& Suhadolnik, D. (1989). Models for HRD practice: The research report. Alexandria, VA: American Society for Training and Development.

3. The work we have done has been published in many places over the last 20 years. A few of those publications include Ulrich, D., Brockbank, W., \& Yeung, A. (1990). Beyond belief: A benchmark for human resources. Human Resource Management, 28(3), 311-335. Ulrich, D., Brockbank, W., Yeung, A., \& Lake, D. (1995). Human resource competencies: An empirical assessment. Human Resource Management, 34(4), 473-496. Yeung, A., Brockbank, W., \& Ulrich, D. (1994). Lower cost, higher value: Human resources function in transition.

Human Resource Planning Journal, 17(3), 1-16. Brockbank, W., \& Ulrich, D. (2003). Competencies for the new HR. Arlington, VA: Society of Human Resource Management.

Brockbank, B., \& Ulrich, D. (in press). HR competencies that make a difference. In J. Storey, P. Wright, \& D. Ulrich (Eds.), Strategic HRM. New York: Routledge.

4. We are grateful for the support of our global partners:

- Society for Human Resource Management (SHRM), a partner in 2002 and 2007, who represented North America;

- IAE, the Management and Business School of Universidad Austral in Argentina, a partner in 2002 and 2007, headed by Professor Alejandro Sioli and Michel Hermans. IAE represented Latin America;

- The Irish Management Institute (IME), headed by Martin Farrelly, with the assistance of Grace Kearns, representing Europe;
- Tsinghua University in Beijing, China, headed by Dr. Xiaoming Zheng and Dr. Felicia Deng;

- The Australian Human Resource Institute (AHRI), who worked in Australia and Asia Pacific, headed by Paul Dainty, with the assistance of Anne Marie Dolan; and

- The National HRD Network in India, which focused on data collection from India, headed by Jagdeep Khandpur.

AR professionals who would have succeeded 30,20, or even 10 years ago would not be as likely to succeed today.

These regional partners took responsibility for identifying companies in their geographic areas and were instrumental in facilitating data collection and analysis. This study would be impossible without their collaboration, and we are very grateful for their active involvement.

5. We should note that in the 2007 study, we had seven categories for education and we combined them to match previous rounds of the study.

6. We are not reporting in this article the statistics behind these findings. These are available from the authors and will be included in a forthcoming book.

7. McGahan, A., \& Porter, M. (1997). How much does industry matter, really? Strategic Management Journal, 18 (Summer special issue), 15-30.

Rumelt, R. (1991). How much does industry matter? Strategic Management Journal, 12(3), 167-185. 
Dave Ulrich is a professor of business at the University of Michigan and a partner at the RBL Group, a consulting firm focused on helping organizations and leaders deliver value. He studies how organizations build capabilities of speed, learning, collaboration, accountability, talent, and leadership through leveraging human resources. He has helped generate award-winning databases that assess alignment between strategies, HR practices, and $H R$ competencies. He has written over 12 books and hundreds of articles. His most recent books are The HR Value Proposition (with Wayne Brockbank) and Leadership Brand (with Norm Smallwood). He has also earned various awards for his research and writing. He may be reached via e-mail at dou@umich.edu, or by visiting www.rbl.net. Wayne Brockbank is a clinical professor of business at the Ross School of Business at the University of Michigan where he codirects the number-one-rated senior HR executive programs. His research and consulting focus is on linkages between HR and business strategy and emerging high value-added agendas of the HR profession. He has been published widely in the Human Resource Management Journal, Human Resource Planning, and Personnel Administrator, and is the coauthor with Dave Ulrich of The HR Value Proposition. He is a principal in RBL Consulting (www.rbl.net) and consults in his areas of expertise with major clients on every continent. He may be contacted via e-mail at wbrock@umich.edu. Dani Johnson heads HR research and product creation for the RBL Group. For the past two years, Johnson has led a global team to conduct the fifth round of the Human Resource Competency Study. Prior to joining the RBL Group, Johnson worked as a project manager at Ford Motor Company. More information about Dani Johnson can be found at www.rbl.net. Jon Younger, PhD, is a principal of the RBL Group and a leader of the firm's strategic HR practice. He is also a director of the RBL Institute. He is the author of a variety of publications in strategic HR and change management, and may be contacted via e-mail at jyounger@rbl.net. 